\title{
Indapamide-Induced Rhabdomyolysis: An Evaluation of Case Reports in VigiBase Using the Bradford Hill Criteria
}

\author{
Qun-Ying Yue ${ }^{1}$ (D) Pia Caduff-Janosa ${ }^{1}$ D
}

Accepted: 8 February 2022 / Published online: 2 March 2022

(c) The Author(s) 2022

\begin{abstract}
Background Indapamide can cause hypokalaemia and hyponatraemia. Rhabdomyolysis associated with these electrolyte abnormalities has been reported.

Objective The aim of this study was to assess causal association between the use of indapamide and the occurrence of rhabdomyolysis using the Bradford Hill criteria.

Methods Variables in the rhabdomyolysis case reports and literature were reviewed. Bradford Hill criteria were used in the assessment of causal association.

Results Up to 11 November 2020, there were 28 unique cases in VigiBase from 13 countries reporting indapamide-associated rhabdomyolysis. In 18 of these cases, hypokalaemia $(n=14)$ or hyponatremia $(n=8)$ was a co-reported event, including four cases where both of these events were reported. Indapamide was the only suspected drug in nine of these 18 cases and positive dechallenge was mentioned in 13 of them. In addition, there were risk factors such as falls, concomitant drugs with risk of hypokalaemia, or muscle injury. In two cases, liquorice (containing glycyrrhizin) was concomitantly used with indapamide before hypokalaemia and rhabdomyolysis occurred. Thiazide diuretics, known to cause hypokalaemia, showed similar disproportionality patterns as indapamide regarding rhabdomyolysis and myopathy, while calcium channel blockers (not causing hypokalaemia), had lower disproportionality values than indapamide.

Conclusions Based on the review of case series and causality assessment using Bradford Hill criteria, indapamide may cause rhabdomyolysis due to hypokalaemia or hyponatremia. Considering the seriousness of the reported cases, health care professionals should be aware of this potential risk following indapamide intake, particularly when there are risk factors for hypokalaemia and hyponatremia such as excessive liquorice consumption. A similar risk of muscle injuries may apply to thiazide diuretics as well.
\end{abstract}

\section{Introduction}

Indapamide is a non-thiazide diuretic, indicated for essential hypertension treatment $[1,2]$. The recommended dose is one tablet containing $2.5 \mathrm{mg}$ daily, which exerts prolonged antihypertensive activity in hypertensive human subjects [1]. In some jurisdictions, indapamide tablets are also approved for the treatment of salt and fluid retention associated with congestive heart failure [2].

Rhabdomyolysis is a condition in which damaged skeletal muscle breaks down rapidly resulting in leakage of the intracellular muscle constituents into the circulation and extracellular fluid. Weakness, myalgia and dark, tea-coloured urine

Qun-Ying Yue

qun-ying.yue@who-umc.org

1 Uppsala Monitoring Centre, Box 1051, 75140 Uppsala, Sweden are the main clinical manifestations. Some of the muscle breakdown products, such as the protein myoglobin, are harmful to the kidneys and may lead to renal failure. Rhabdomyolysis ranges from an asymptomatic illness with elevation in creatine kinase activity, to a life-threatening condition associated with extreme elevations in creatine kinase, electrolyte imbalances, acute renal failure, and disseminated intravascular coagulation [3-5].

The causes of rhabdomyolysis include muscular trauma, muscle enzyme deficiencies, electrolyte abnormalities, infections, drugs, toxins, and endocrinopathies [3-5]. Among electrolyte imbalances, the following have been listed as causes of rhabdomyolysis: hyperosmotic conditions, hypernatremia, hypocalcaemia, hyponatremia, hypokalaemia [6], and hypophosphatemia. Drugs that may induce rhabdomyolysis have been summarised including statins and other antilipid agents, antipsychotics and antidepressants, 


\section{Key Points}

Indapamide can cause hypokalaemia and hyponatremia. Rhabdomyolysis associated with these electrolyte abnormalities has been reported in literature.

Based on the review of case series and causality assessment using Bradford Hill criteria, indapamide may cause rhabdomyolysis due to hypokalaemia or hyponatremia. Muscle injury and concomitant use of other drugs that cause hypokalaemia appear to be risk factors.

Health care professionals should be aware of the potential risk of rhabdomyolysis associated with indapamide, particularly when there are other risk factors for hypokalaemia or hyponatraemia. A risk of muscle injuries may apply to thiazide diuretics as well.

sedative hypnotics, drugs of addiction, antihistamines and other drugs [3-5] such as thiazides [5].

Rhabdomyolysis is not labelled in the UK or US indapamide product information; however, electrolyte imbalances such as hypokalaemia and hyponatremia are labelled in both the UK and US [1, 2]. In addition, "muscle pains or cramps" are mentioned in the US label, as part of warning signs for hypokalaemia, hyponatremia and other fluid and electrolyte imbalances. Plasma sodium and potassium must be measured before starting indapamide treatment, then at regular intervals subsequently, to prevent hyponatremia and hypokalaemia, in particular in certain high-risk populations [2].

The aim of this study was to assess the causal association between the use of indapamide and the occurrence of rhabdomyolysis.

\section{Methods}

The combination of indapamide and rhabdomyolysis (MedDRA preferred term) was first detected in a screening of VigiBase, the WHO global database of reported potential side effects of medicinal products. VigiBase is the largest database of its kind in the world, with over 25 million reports of potential side effects of medicinal products, submitted, since 1968 , by over 140 member countries of the WHO Programme for International Drug Monitoring [7]. The signal detection activity was supported by vigiRank [8], which is a data-driven predictive model for emerging safety signals. In addition to disproportionate reporting patterns [9], it also accounts for the completeness, recency, and geographic spread of individual case reporting, as well as the availability of case narratives. A clinical review of reports with rhabdomyolysis associated with indapamide in VigiBase up to 11 November 2020 was performed, with duplicates excluded. For the case series assessment on causal relationship, the Bradford Hill criteria [10-13] were applied, which include:

- strength of association ( $\mathrm{IC}_{025}$ for indapamide /rhabdomyolysis),

- consistency (similar observation in other data sources),

- specificity (specifically associated with hypokalaemia and hyponatraemia),

- temporality (consistency of the time to onset),

- biological gradient (dose-related pattern),

- plausibility of the association (proposed mechanism),

- coherence (makes sense based on other known causes of rhabdomyolysis),

- experimental evidence (effect of dechallenge/rechallenge)

- analogy (documented association with other K+ wasting medicines).

Searches on indapamide-associated myopathy (MedDRA preferred term) and on thiazide diuretics (ATC C03A) -associated rhabdomyolysis and myopathy were also performed in VigiBase up to 11 November 2020 to assess the consistency and analogy of the association between indapamide and these muscle disorders. The corresponding searches for calcium channel blockers (CCBs) were performed 1 week later. The number of reported (observed) versus expected cases, the information component (IC) and its lower limit of a $95 \%$ credibility interval $\left(\mathrm{IC}_{025}\right)$ values were employed as measures of disproportionality, which were used in the comparison between indapamide and thiazide diuretics or CCBs. The expected value is based on the total number of reports concerning indapamide and the proportion of cases reporting rhabdomyolysis and myopathy in the whole database. The positive IC values indicate disproportional reporting, but there is a significant disproportionality only when $\mathrm{IC}_{025}$ value is positive.

\section{Results}

Data are presented and analysed based on each of the Bradford Hill criteria.

\subsection{Strength of Association (IC $\mathrm{I}_{025}$ for Indapamide/ Rhabdomyolysis)}

VigiBase contained 33 cases reporting rhabdomyolysis with indapamide as a suspected or interacting medicine (expected 15). The $\mathrm{IC}_{025}$ was 0.5 , indicating a statistical safety signal. Compared with the combination indapamide 
and myopathy, the higher $\mathrm{IC}_{025}$ values for rhabdomyolysis suggest a stronger signal. Therefore, an in-depth evaluation was performed for rhabdomyolysis.

The findings on thiazides and CCBs in Table 1 support the Bradford Hill analogy and specificity criteria, respectively (see sections 3.9 and 4).

\subsection{Consistency (Similar Observation in Other Data Sources)}

The reports came from 13 countries (mostly from France, Australia, Italy, Japan and Spain). Indapamide-induced acute hypokalaemic rhabdomyolysis has also been reported in literature $[14,15]$.

\subsection{Specificity (Specifically Associated with Hypokalaemia and Hyponatraemia)}

After excluding five duplicates, 28 cases remained including 18 cases with informative narratives. Of these, $82 \%(n=23)$ were recorded as serious; when the criteria for seriousness was known $(n=19)$, only one case was recorded as other medically important condition, with the rest having caused or prolonged hospitalisation, including one in intensive care, and four being life threatening. When information on reporter qualification was provided $(n=25)$, the cases were all reported by a physician except one case by a consumer/ non-health professional, which was a case report in literature [14]. There were 16 females and 12 males, with an age range between 42 and 81 years (median 68 years) where information was given $(n=24)$.

\subsubsection{Cases of Indapamide-Associated Rhabdomyolysis with Co-reported Hypokalaemia or Hyponatraemia}

In 18 of the 28 indapamide-associated rhabdomyolysis cases, hypokalaemia $(n=14)$ or hyponatraemia $(n=8)$ was a co-reported event, including four cases where both these events were co-reported (see Table 2). Indapamide was the only suspected drug in nine of these 18 cases.

In two cases ( 7 and 10 in Table 2), liquorice (containing glycyrrhizin; used in traditional Asian medicine for its antiinflammatory properties) was added to long-term indapamide treatment before hypokalaemia and rhabdomyolysis were reported.

(1) 65-year-old male. Simvastatin (40 mg per day) and indapamide ( $1.5 \mathrm{mg}$ per day) were started 21 and 18 months before the occurrence of hypokalaemia and rhabdomyolysis, and discontinued at the onset of these events. The reaction diminished after the drugs were withdrawn. It was reported that the patient had relatively high consumption of liquorice (approximately $100 \mathrm{~g}$ per day) before the occurrence of hypokalaemia and rhabdomyolysis [15].

(2) 77-year-old female. Indapamide, candesartan and loxoprofen were started 3 years before the occurrence of pseudoaldosteronism and rhabdomyolysis. Liquorice $7.5 \mathrm{~g}$ per day was started two months before these events. All the products were discontinued at the onset of these events and the reaction abated upon drug withdrawal.

Table 1 Disproportionality of reports on rhabdomyolysis and myopathy associated with indapamide (ATC C03BA11), thiazide diuretics (C03A) and calcium channel blockers (C08C) in VigiBase

\begin{tabular}{|c|c|c|c|c|c|c|}
\hline \multirow[t]{2}{*}{ Active ingredient(s)/ MedDRA preferred terms (PTs) } & \multicolumn{6}{|c|}{ Disproportionality values for single or groups of drugs } \\
\hline & $N$ observed & $N$ expected & $N$ drug & $N$ reaction & $\mathrm{IC}_{025}$ & IC \\
\hline Indapamide/ rhabdomyolysis & 33 & 15 & 10,863 & 32,557 & 0.5 & 1.1 \\
\hline Indapamide/ myopathy & 11 & 5 & 10,863 & 10,666 & 0.1 & 1.1 \\
\hline Thiazides (ATC C03A)/ rhabdomyolysis ${ }^{a}$ & 82 & 44 & 30,844 & 32,557 & 0.6 & 0.9 \\
\hline Thiazides (ATC C03A)/ myopathy ${ }^{\mathrm{b}}$ & 24 & 14 & 30,844 & 10,666 & 0.1 & 0.7 \\
\hline CCB (ATC C08C)/ rhabdomyolysis ${ }^{\mathrm{c}}$ & 323 & 236 & 167,329 & 32,565 & 0.3 & 0.4 \\
\hline CCB (ATC C08C)/ myopathy ${ }^{\mathrm{d}}$ & 71 & 78 & 167,329 & 10,676 & -0.5 & -0.1 \\
\hline
\end{tabular}

$C C B$ calcium channel blockers, $I C$ information component, $I C_{025}$ lower limit of a $95 \%$ credibility interval for the IC

${ }^{\mathrm{a}} \mathrm{The} \mathrm{IC}_{025}$ was positive for bendroflumethiazide, hydrochlorothiazide and trichlormethiazide; negative for bendroflumethiazide; potassium

${ }^{\mathrm{b}} \mathrm{The} \mathrm{IC}_{025}$ was positive for trichlormethiazide, and negative for hydrochlorothiazide, bendroflumethiazide and polythiazide, although the IC value was positive for all these drugs

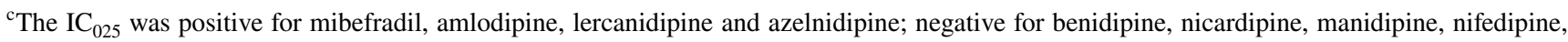
cilnidipine, felodipine, barnidipine, nitrendipine, lacidipine and nimodipine

${ }^{\mathrm{d}} \mathrm{The} \mathrm{IC}_{025}$ was positive for mibefradil and lercanidipine, negative for amlodipine, isradipine, nifedipine, efonidipine, nitrendipine and felodipine 


\subsubsection{Cases of Indapamide-Associated Rhabdomyolysis Without Co-Reported Hypokalaemia or Hyponatraemia}

In the remaining ten cases (Table 3), without co-reported hypokalaemia or hyponatraemia, there were multiple cosuspected or concomitant medicines with known risks of muscle injury (e.g. statins or gemfibrozil, $n=5$ ). Indapamide was the single suspected drug in only one of these cases and positive dechallenge was mentioned in two of them.

\subsection{Temporality (Consistency of the Time to Onset)}

Among the cases in Table 2 with co-reported hypokalaemia or hyponatraemia in VigiBase $(n=18)$, the time from indapamide start to the onset of rhabdomyolysis ranged from 3 days to 21 months in 11 cases where this information was available (within 15 days in five cases, 1-2 months in three cases, between 12 months and 21 months in three cases).

Among the cases in Table 3 without co-reported hypokalaemia or hyponatraemia, the time to onset was provided in only two of the cases (i.e. 2 and 3 months, respectively).

Most of the cases occurred within 1 month, supporting a temporal relationship. In the above-mentioned two cases involving liquorice, a closer temporal relationship was observed for the addition of liquorice to long-term indapamide treatment before hypokalaemia and rhabdomyolysis occurred, suggesting a role of liquorice or the possible consequence of an interaction.

\subsection{Biological Gradient (Dose-Related Pattern)}

The indapamide dose was known in 17 of the 28 cases: $1.0-2.5 \mathrm{mg}$ daily in 15 patients, and $5 \mathrm{mg}$ daily in two patients.

When comparing the groups of patients with versus without co-reported hypokalaemia or hyponatraemia, the daily dose seems to be somewhat higher in patients with the electrolyte disorders (median $2.0 \mathrm{mg}$, ranging $1.0-5.0 \mathrm{mg}$; mean $2.4 \mathrm{mg}$; Table 2) than in those without hypokalaemia or hyponatraemia (median $1.5 \mathrm{mg}$, ranging $1.5-2.5 \mathrm{mg}$; mean $1.8 \mathrm{mg}$; Table 3).

\subsection{Plausibility of the Association (Proposed Mechanism)}

Among the 28 reported cases of indapamide-associated rhabdomyolysis, 18 (64\%) of them co-reported hypokalaemia. Hypokalaemic rhabdomyolysis has been reported in literature, with [16] or without $[6,17]$ concomitant intake of liquorice, a substance known to cause hypokalaemia [18-20].
Hyponatraemia has also been reported in eight of the 28 cases, with $(n=4)$ or without $(n=4)$ hypokalaemia, in line with literature findings [21].

Indapamide is known to cause both hyperkalaemia and hyponatraemia $[1,2]$.

\subsection{Coherence (Makes Sense Based on Other Known Causes of Rhabdomyolysis)}

In the cases without hypokalaemia or hyponatraemia being co-reported, some other factors such as muscle injury (fall, use of statins or fibrates) and concomitant use of other drugs that cause hypokalaemia (such as thiazides) could be an alternative or contributing explanation for the suspecting indapamide-related rhabdomyolysis. On the other hand, the absence of reporting for hypokalaemia or hyponatraemia in some cases of the series may not be the same as evidence of absence of hypokalaemia or hyponatraemia, since the latter may have not been measured, suspected or reported.

\subsection{Experimental Evidence (Effect of Dechallenge/ Rechallenge)}

There were no cases with positive rechallenge. However, positive de-challenge was mentioned in 13 of the 18 cases with hypokalaemia reported with rhabdomyolysis.

\subsection{Analogy (Documented Association with Other Potassium-Wasting Medicines)}

Other potassium-wasting medicines such thiazide diuretics (e.g. hydrochlorothiazide) are known to cause disturbances in the electrolyte imbalance. Hypokalaemia and hyponatraemia are among the very common adverse reactions of these drugs [2, 22, 23]. Association between rhabdomyolysis and thiazide diuretics have been reported rarely in literature [21, 24-26]. Also, thiazide is listed among the drugs that can cause rhabdomyolysis. This supports the Bradford Hill consistency and analogy criteria for the causality assessment [5].

\subsubsection{Reporting of Rhabdomyolysis and Myopathy Associated with Thiazide Diuretics (ATC C03A) and CCB (ATC C08C) in Comparison with Indapamide}

The disproportionality values for a single drug or groups of drugs are shown in Table 1. For indapamide, the $\mathrm{IC}_{025}$ for myopathy was positive, although lower compared with rhabdomyolysis, being 0.1 and 0.5 , respectively. As with indapamide, the $\mathrm{IC}_{025}$ was positive for thiazide diuretics (ATC C03A) in respect of myopathy and rhabdomyolysis, being 0.1 and 0.6 , respectively. By contrast, the $\mathrm{IC}_{025}$ was 
Table 2 Cases of indapamide-associated rhabdomyolysis with co-reported hypokalaemia or hyponatraemia in VigiBase $(n=18)$

\begin{tabular}{|c|c|c|c|c|c|c|c|}
\hline Case & Age/ sex & $\begin{array}{l}\text { Suspected (S), interact- } \\
\text { ing (I) or concomitant } \\
\text { (C) drugs }\end{array}$ & $\begin{array}{l}\text { Indapamide } \\
\text { dose }(\mathrm{mg} / \\
\text { day) }\end{array}$ & $\begin{array}{l}\text { Reactions other than } \\
\text { rhabdomyolysis }\end{array}$ & Time to onset & Reporter category & Additional Information \\
\hline 1 & $-/ F$ & $\begin{array}{l}\text { Indapamide, alpra- } \\
\text { zolam, perindopril, } \\
\text { lercanidipine (all S) }\end{array}$ & 1.5 & $\begin{array}{l}\text { Hypokalaemia } \\
\text { Hyponatraemia } \\
\text { Fall }\end{array}$ & & Physician & Positive dechallenge \\
\hline 2 & $-/ \mathrm{M}$ & Indapamide (S) & & $\begin{array}{l}\text { Hypokalaemia } \\
\text { Asthenia } \\
\text { Gait disturbance } \\
\text { Alkalosis metabolic }\end{array}$ & & Physician & Positive dechallenge \\
\hline 3 & $80 / \mathrm{F}$ & $\begin{array}{l}\text { Indapamide }(\mathrm{S}) \\
\text { Omeprazole, lovastatin, } \\
\text { paracetamol (all C) }\end{array}$ & 5.0 & Hypokalaemia & $21 \mathrm{mo}$ & Physician & $\begin{array}{l}\text { Positive dechallenge, } \\
\text { omeprazole ( } 2 \mathrm{mo}) \\
\text { lovastatin (4 y) }\end{array}$ \\
\hline 4 & $69 / \mathrm{M}$ & $\begin{array}{l}\text { Indapamide (S) } \\
\text { Insulin, sitagliptin, } \\
\text { metformin, esome- } \\
\text { prazole, amlodipine, } \\
\text { irbesartan, fexofena- } \\
\text { dine (all C) }\end{array}$ & 1.0 & Hyponatraemia & $1 \mathrm{mo}$ & Physician & Positive dechallenge \\
\hline 5 & $81 / \mathrm{F}$ & $\begin{array}{l}\text { Indapamide, solifena- } \\
\text { cin, paroxetine, rilme- } \\
\text { nidine, zopiclone, } \\
\text { alprazolam (all S) }\end{array}$ & & $\begin{array}{l}\text { Hyponatraemia } \\
\text { Fall } \\
\text { Hypochloraemia } \\
\text { Confusional state } \\
\text { Acute urine retention } \\
\text { Urinary tract infection }\end{array}$ & & Physician & Positive dechallenge \\
\hline 6 & $81 / \mathrm{F}$ & Indapamide (S) & & $\begin{array}{c}\text { Hypokalaemia (lowest } \\
\text { K level } 2.4 \mathrm{mEq} / \mathrm{L})\end{array}$ & & Physician & Positive dechallenge \\
\hline 7 & $65 / \mathrm{M}$ & $\begin{array}{l}\text { Indapamide, Glycyr- } \\
\text { rhiza glabra (both I) } \\
\text { Simvastatin (S) } \\
\text { Allopurinol, metformin } \\
\text { (both C) }\end{array}$ & 1.5 & $\begin{array}{l}\text { Hypokalaemia (lowest } \\
\mathrm{K} \text { level } 1.5 \mathrm{mEq} / \mathrm{L}) \\
\text { Drug interaction }\end{array}$ & $18 \mathrm{mo}$ & Physician & $\begin{array}{l}\text { Positive dechallenge, } \\
\text { simvastatin ( } 21 \mathrm{mo}) \\
\text { Glycyrrhiza glabra }\end{array}$ \\
\hline 8 & $63 / \mathrm{M}$ & Indapamide $(\mathrm{S})$ & & Hypokalaemia (severe) & $11 \mathrm{~d}$ & $\begin{array}{l}\text { Consumer/ non- } \\
\text { health profes- } \\
\text { sional }\end{array}$ & $\begin{array}{l}\text { Literature case [14] } \\
\text { Positive dechallenge }\end{array}$ \\
\hline 9 & $76 / F$ & $\begin{array}{l}\text { Indapamide (S) } \\
\text { Atorvastatin, beclo- } \\
\text { metasone, glime- } \\
\text { piride, metformin, } \\
\text { pregabalin (all C) }\end{array}$ & 1.5 & $\begin{array}{l}\text { Hyponatraemia (lowest } \\
\text { Na level } 111 \mathrm{mEq} / \mathrm{L} \text { ) } \\
\text { Diarrhoea, syncope }\end{array}$ & & Physician & $\begin{array}{l}\text { Intensive care } \\
\text { Positive dechallenge }\end{array}$ \\
\hline 10 & $77 / F$ & $\begin{array}{l}\text { Indapamide, Glycyr- } \\
\text { rhiza spp; Paeonia } \\
\text { lactiflora, candesar- } \\
\text { tan, loxoprofen (all S) } \\
\text { Nifedipine (C) }\end{array}$ & 2.0 & $\begin{array}{l}\text { Hypokalaemia (lowest } \\
\text { K level } 1.6 \mathrm{mEq} / \mathrm{L}) \\
\text { Pseudoaldosteronism }\end{array}$ & $2 \mathrm{mo}$ & Physician & $\begin{array}{l}\text { Positive dechallenge, } \\
\text { Glycyrrhiza spp. }\end{array}$ \\
\hline 11 & $71 / \mathrm{F}$ & $\begin{array}{l}\text { Indapamide, atorvasta- } \\
\text { tin (both I) }\end{array}$ & 2.5 & $\begin{array}{l}\text { Hypokalaemia (lowest } \\
\text { K level } 2.5 \mathrm{mEq} / \mathrm{L}) \\
\text { Hyponatraemia } \\
\text { Hypomagnesaemia } \\
\text { Proximal myopathy }\end{array}$ & $12 \mathrm{mo}$ & Physician & $\begin{array}{l}\text { Positive dechallenge, } \\
\text { atorvastatin } 5 \mathrm{y}\end{array}$ \\
\hline 12 & $60 / \mathrm{F}$ & $\begin{array}{l}\text { Indapamide, levothy- } \\
\text { roxine (both S) }\end{array}$ & 1.5 & $\begin{array}{l}\text { Hypokalaemia } \\
\text { Hyponatraemia } \\
\text { Confusion }\end{array}$ & $4 \mathrm{~d}$ & Physician & $\begin{array}{l}\text { Indapamide } 4 \mathrm{~d} \\
\text { Levothyroxine } 3 \mathrm{y}\end{array}$ \\
\hline 13 & $77 / \mathrm{F}$ & $\begin{array}{l}\text { Indapamide, spirono- } \\
\text { lactone, fenofibrate } \\
\text { (all S) }\end{array}$ & 5.0 & $\begin{array}{l}\text { Hyponatraemia (lowest } \\
\text { Na level } 124 \text { mEq/L) }\end{array}$ & & Physician & Positive dechallenge \\
\hline 14 & $79 / F$ & $\begin{array}{l}\text { Indapamide, terbuta- } \\
\text { line, iron, amitripty- } \\
\text { line, alendronic acid } \\
\text { (all S) }\end{array}$ & 2.5 & $\begin{array}{l}\text { Hypokalaemia } \\
\text { Hyponatraemia } \\
\text { Syncope }\end{array}$ & & Physician & \\
\hline
\end{tabular}


Table 2 (continued)

\begin{tabular}{|c|c|c|c|c|c|c|c|}
\hline Case & Age/ sex & $\begin{array}{l}\text { Suspected (S), interact- } \\
\text { ing (I) or concomitant } \\
\text { (C) drugs }\end{array}$ & $\begin{array}{l}\text { Indapamide } \\
\text { dose }(\mathrm{mg} / \\
\text { day) }\end{array}$ & $\begin{array}{l}\text { Reactions other than } \\
\text { rhabdomyolysis }\end{array}$ & Time to onset & Reporter category & Additional Information \\
\hline 15 & $51 / \mathrm{M}$ & $\begin{array}{l}\text { Indapamide (S) } \\
\text { Nifedipine, atenolol } \\
\quad \text { (both C) }\end{array}$ & & Hypokalaemia & $2 \mathrm{mo}$ & & \\
\hline 16 & 48/M & $\begin{array}{l}\text { Indapamide, colchicine, } \\
\text { Papaver somniferum, } \\
\text { tiemonium (all S) }\end{array}$ & & Hypokalaemia & $15 \mathrm{~d}$ & Physician & \\
\hline 17 & $42 / \mathrm{F}$ & $\begin{array}{l}\text { Indapamide (S) } \\
\text { Captopril (C) }\end{array}$ & 2.5 & Hypokalaemia & $15 \mathrm{~d}$ & Physician & Positive dechallenge \\
\hline 18 & $61 / \mathrm{M}$ & Indapamide (S) & & Hypokalaemia & $3 \mathrm{~d}$ & & \\
\hline
\end{tabular}

$F$ female, $d$ day, $M$ male, mo month, $y$ year

negative for $\mathrm{CCB}(\mathrm{C} 08 \mathrm{C})$ for myopathy and only positive for rhabdomyolysis, being -0.5 and 0.3 , respectively.

Among the cases in VigiBase of rhabdomyolysis associated with indapamide, thiazide diuretics and CCBs, the most commonly (top three) co-reported drugs were

- for indapamide: metformin $(n=5$, including suspected $n=1$ and concomitant $n=4)$, simvastatin $(n=4$, all suspected) and perindopril ( $n=4$, all suspected);

- for thiazide diuretics: $\operatorname{simvastatin}(n=25$, including suspected $n=22$, and concomitant $n=3$ ), acetylsalicylic acid ( $n=20$, including suspected $n=13$ and concomitant $n=7)$, and ramipril ( $n=18$, including suspected $n=16$ and concomitant $n=2)$;

- for CCBs: simvastatin ( $n=105$, including suspected $n=104$ and concomitant $n=1)$, atorvastatin $(n=42$, including suspected $n=40$ and concomitant $n=2$ ) and furosemide ( $n=32$, including suspected $n=17$ and concomitant $n=15$ ), respectively.

The most concomitantly reported ADRs (adverse drug reactions) included hypokalaemia, hyponatraemia and myalgia for indapamide; acute kidney injury, hypokalaemia and hyponatraemia for thiazide diuretics; and creatine phosphokinase blood level (B-CPK) increase, acute kidney injury and drug interaction for CCBs, respectively.

The similar disproportional reporting pattern regarding both myopathy and rhabdomyolysis as well as the most commonly co-reported hypokalaemia and hyponatraemia for thiazide diuretics and indapamide, also in line with literature findings, supports the Bradford Hill analogy criteria for the causality assessment. Although the association between the muscle disorders and thiazide use has not been further evaluated in depth with VigiBase data, the similar reporting pattern is in line with literature findings regarding rhabdomyolysis related to hypokalaemia and hyponatraemia for both thiazide diuretics and indapamide.
There was, however, no disproportionality for myopathy associated with CCBs, which are not known for inducing hypokalaemia with their routine clinical use [19]. Indeed, while hypokalaemia and hyponatraemia are commonly coreported for cases of rhabdomyolysis with indapamide and thiazide diuretics, this is not the case for CCBs. In addition, statins and furosemide are the most commonly co-reported medications among CCB-associated rhabdomyolysis, which likely would have explained or contributed to the disproportional reporting.

The use of CCBs as a 'negative' control supports the specificity of Bradford Hill criteria.

\section{Discussion}

The aim of this study was to assess the causal association between the use of indapamide and the occurrence of rhabdomyolysis using the Bradford Hill criteria.

The significant disproportional reporting (i.e. a positive $\mathrm{IC}_{025}$ value for indapamide/rhabdomyolysis) supports the strength of the association. Similar cases of hypokalaemic rhabdomyolysis in literature supports the consistency. Most of the cases in the series having co-reported hypokalaemia with or without hyponatraemia supports the specificity. Most of the cases having occurred within 1 month of indapamide use supports the temporality. Somewhat higher doses seen in cases with co-reported hypokalaemia and/or hyponatraemia supports biological gradient. The proposed mechanism (i.e. indapamide being able to cause hypokalaemia and hyponatraemia, which could induce rhabdomyolysis) supports plausibility. The existence of other known causes of rhabdomyolysis, as potential risk factors, may support coherence of the association. Finally, thiazide diuretics being on the list of drugs causing rhabdomyolysis, as well as case reports of thiazide-induced rhabdomyolysis due to hypokalaemia or hyponatraemia in literature, support analogy of 
Table 3 Cases of indapamide-associated rhabdomyolysis without co-reported hypokalaemia or hyponatraemia in VigiBase $(n=10)$

\begin{tabular}{|c|c|c|c|c|c|c|c|}
\hline Case & Age/ Sex & $\begin{array}{l}\text { Suspected (S), inter- } \\
\text { acting (I) or concomi- } \\
\text { tant (C) drugs }\end{array}$ & $\begin{array}{l}\text { Indapamide } \\
\text { dose }(\mathrm{mg} / \\
\text { day) }\end{array}$ & $\begin{array}{l}\text { Reactions other than } \\
\text { rhabdomyolysis }\end{array}$ & Time to onset & Reporter category & $\begin{array}{l}\text { Additional Informa- } \\
\text { tion }\end{array}$ \\
\hline 1 & $62 / \mathrm{F}$ & $\begin{array}{l}\text { Indapamide, irbe- } \\
\text { sartan, digoxin, } \\
\text { fluindione, man- } \\
\text { idipine, alendronic } \\
\text { acid, colecalciferol } \\
\text { (all S) }\end{array}$ & 1.5 & & & Physician & \\
\hline 2 & $59 / \mathrm{M}$ & $\begin{array}{l}\text { Indapamide, atorvas- } \\
\text { tatin, omeprazole, } \\
\text { lercanidipine, } \\
\text { celiprolol, alfuzo- } \\
\text { sin, glibenclamide } \\
\text { (all S) }\end{array}$ & 1.5 & $\begin{array}{l}\text { Hepatic injury, chol- } \\
\text { estasis }\end{array}$ & & Physician & $\begin{array}{l}\text { Atorvastatin } \\
80 \mathrm{mg} / \mathrm{d}\end{array}$ \\
\hline 3 & $73 / \mathrm{F}$ & $\begin{array}{l}\text { Indapamide, esome- } \\
\text { prazole, hydrochlo- } \\
\text { rothiazide; telmisar- } \\
\text { tan, acetylsalicylic } \\
\text { acid, salbutamol } \\
\text { (all S) }\end{array}$ & 1.5 & Mucositis NOS & & Pharmacist & \\
\hline 4 & $54 / \mathrm{M}$ & $\begin{array}{l}\text { Indapamide, simvas- } \\
\text { tatin (both S) }\end{array}$ & & & & Physician & Positive dechallenge \\
\hline 5 & $67 / \mathrm{F}$ & $\begin{array}{l}\text { Indapamide, } \\
\text { ezetimibe/simvas- } \\
\text { tatin, hydrochloro- } \\
\text { thiazide }+14 \text { drugs } \\
\text { (all S) }\end{array}$ & & $\begin{array}{l}\text { Drug interaction } \\
\text { Renal failure acute }\end{array}$ & & Physician & $\begin{array}{l}\text { Positive dechallenge } \\
\text { for ezetimibe/ } \\
\text { simvastatin }\end{array}$ \\
\hline 6 & $69 / \mathrm{M}$ & $\begin{array}{l}\text { Indapamide, } \\
\text { benazepril, amlodi- } \\
\text { pine (all S) }\end{array}$ & & Myalgia & & Physician & \\
\hline 7 & $55 / \mathrm{F}$ & $\begin{array}{l}\text { Indapamide, perin- } \\
\text { dopril, gliclazide } \\
\text { (all S) } \\
\text { Metformin (C) }\end{array}$ & 2.5 & Hypoglycaemia & $3 \mathrm{mo}$ & & \\
\hline 8 & $75 / \mathrm{M}$ & $\begin{array}{l}\text { Indapamide, gemfi- } \\
\text { brozil, simvastatin, } \\
\text { acetylsalicylic acid, } \\
\text { celecoxib, quinapril } \\
\text { (all S) }\end{array}$ & 2.5 & Renal failure acute & 2 mo for simvastatin & Physician & $\begin{array}{l}\text { Gemfibrozil } 1.2 \mathrm{~g} \\
\text { Simvastatin } 80 \mathrm{mg}\end{array}$ \\
\hline 9 & $-/ M$ & $\begin{array}{l}\text { Indapamide (S) } \\
\text { Verapamil (C) }\end{array}$ & & Renal failure & & Physician & \\
\hline 10 & $-/ F$ & $\begin{array}{l}\text { Indapamide, mor- } \\
\text { phine, perindopril, } \\
\text { zolpidem (all S) } \\
\text { Levothyroxine, carba- } \\
\text { mazepine, amlodi- } \\
\text { pine, atorvastatin, } \\
\text { pregabalin (all C) }\end{array}$ & 1.5 & $\begin{array}{l}\text { Bladder dilatation, } \\
\text { coma, miosis, } \\
\text { bradypnoea, acute } \\
\text { kidney injury }\end{array}$ & & Physician & Positive dechallenge \\
\hline
\end{tabular}

$F$ female, $d$ day, $M$ male, mo month, $y$ year, NOS not otherwise specified

Bradford Hill criteria [3 ref]. In addition, the use of CCBs as a 'negative' control also supports specificity.

Hypokalaemia is the most common electrolytic cause of rhabdomyolysis [4]. Rhabdomyolysis is usually associated with hyperkalaemia due to renal failure or leakage of potassium from skeletal muscle and hence hypokalaemia as a cause of rhabdomyolysis can be missed [17].The association of hypokalaemia with rhabdomyolysis has been highlighted $[6,17]$. There have been reports of rhabdomyolysis occurring with severe hypokalaemia with serum potassium levels $<2 \mathrm{mmol} / \mathrm{L}$. It is well known that indapamide may result in hypokalaemia [1] because it can cause excess potassium loss in the urine. 
The mechanism of hypokalaemia-related rhabdomyolysis has been discussed in the literature [17, 27-30]. Potassium plays a major role in regulating the skeletal muscle blood flow; an increased potassium concentration in the muscle during muscle activity causes vasodilatation, which increases the regional blood flow. In a state of hypokalaemia, this increase is hampered, causing relative ischaemia in the active muscle leading to muscle cramps, and in a severely depleted state may cause rhabdomyolysis. In addition to hypoperfusion, hypokalaemia-induced impairment in muscle metabolism may also contribute to muscle dysfunction.

Liquorice ingestion has also been associated with hypokalaemia-induced muscular weakness or rhabdomyolysis [16, 18]. The reason why glycyrrhizin, contained in liquorice, causes hypokalaemia is because inhibition of $11 \beta$-steroid dehydrogenase prevents conversion of cortisol to cortisone, so cortisol continues to work on mineralocorticoid receptors leading to further potassium excretion [19]. Two cases in this study had liquorice added to long-term indapamide treatment before hypokalaemia and rhabdomyolysis occurred. This indicates that these patients may have developed rhabdomyolysis due to severe hypokalaemia, induced by a pharmacodynamic interaction between liquorice and indapamide. The United States Food and Drug Administration (FDA) has warned about over-consumption of black liquorice candy and the risk of hypokalaemia, since it contains the compound glycyrrhizin, which is the sweetening compound derived from liquorice root [20].

In addition, hyponatraemia-associated rhabdomyolysis has been reported in the literature where a case report together with a literature review was presented [21]. Among the 24 published cases of hyponatraemia-induced rhabdomyolysis, 12 had coexisting hypokalaemia which could have played an additional role in the development of rhabdomyolysis. The mechanism by which hyponatraemia causes rhabdomyolysis is unclear and has been discussed [21, 31].

The association between rhabdomyolysis and indapamide is consistent with the findings on rhabdomyolysis and thiazide diuretics, which are also known to give rise to hypokalaemia and hyponatraemia [22, 23]. In addition, hyponatraemia- and hypokalaemia-associated rhabdomyolysis after thiazide diuretic use have been reported [24-26]. Also, thiazide is among the drugs that can cause rhabdomyolysis [5]. This supports the Bradford Hill analogy criteria for the causal relationship assessment. There was, however, no disproportionality for myopathy associated with CCBs, which are not known for inducing hypokalaemia with their routine clinical use [32]. Indeed, while hypokalaemia and hyponatraemia are commonly co-reported for cases of rhabdomyolysis with indapamide and thiazide diuretics in VigiBase, this is not the case for CCBs. In addition, statins and furosemide are the most commonly co-reported medications among CCB-associated rhabdomyolysis, which likely would have explained or contributed to the disproportional reporting. Clinically, treatment recommendations sometimes propose switching hyponatraemic patients on other antihypertensive agents to CCBs [33].

\subsection{Limitations of the Study}

Due to the nature of spontaneous reporting, it is not possible to measure the magnitude of the risk in VigiBase as not all cases occurring are reported and exposure to the drug is unknown. It is possible that indapamide-associated hypokalaemic rhabdomyolysis is underestimated, as significant and widespread under-reporting of ADRs to spontaneous reporting systems including serious or severe ADRs is well known [34]. In this particular case, hypokalaemia as a cause of rhabdomyolysis might be missed clinically since rhabdomyolysis is usually associated with hyperkalaemia, as discussed above. In addition, there might be limited details in the reports regarding, for example, how the diagnosis was made, the exact timing of possible dose changes as well as the use of concomitant drugs, and also quantity and quality of the liquorice taken by the patients.

\section{Conclusion}

Hypokalaemia and hyponatraemia are known adverse reactions of indapamide. Rhabdomyolysis related to severe hypokalaemia and/or hyponatraemia has been reported in VigiBase and in literature. Based on the review of case series and causality assessment using Bradford Hill criteria, indapamide may cause rhabdomyolysis due to hypokalaemia or hyponatraemia. Muscle injury and concomitant use of other drugs that cause hypokalaemia appear to be risk factors. Health care professionals should be aware of the potential risks of rhabdomyolysis associated with indapamide, particularly when there are other risk factors for hypokalaemia or hyponatraemia. A similar risk of hypokalaemic muscle injury may also apply to thiazide diuretics. However, further study is required before recommending that clinicians begin monitoring patients for this adverse event.

Acknowledgements The authors would like to thank Henric Taavola, a senior data scientist, for his help in the signal detection activities; and Niklas Norén, the Chief Science Officer at Uppsala Monitoring Centre, for valuable comments on the manuscript.

\section{Declarations}

Funding No sources of funding were used to assist the preparation of this study.

Disclosures The authors are indebted to the national centres that make up the WHO Programme for International Drug Monitoring and con- 
tribute reports to VigiBase. However, the opinions and conclusions of this study are not necessarily those of the various centres, nor of WHO.

Conflicts of interest/Competing interests Qun-Ying Yue and Pia Caduff-Janosa have no conflicts of interest that are directly relevant to the content of this study.

Ethics approval This article is result of routine work of Uppsala Monitoring Centre. Ethical approval was not required for this study. The reports shared within the WHO Programme are deidentified, and research based on this data is not subject to ethics approval or informed consent.

\section{Consent to participate Not applicable.}

Consent for publication Not applicable.

Availability of data and material The datasets generated and analysed during the current study are not publicly available due to agreements between contributors of data to the database used (VigiBase) and the custodian of this database. National centres (mainly national drug regulatory authorities) constituting the WHO Programme for International Drug Monitoring (PIDM) contribute data to VigiBase and the Uppsala Monitoring Centre is the custodian in its capacity as WHO collaborating centre for international drug monitoring. Some subsets of the data may be available from the corresponding author on reasonable request.

Code availability Not applicable.

Contributions of authors statement Dr. Yue designed and performed the study, and wrote the paper. Dr Caduff-Janosa conceived the study and revised the manuscript content. Both authors approved the final version of the manuscript.

Open Access This article is licensed under a Creative Commons Attribution-NonCommercial 4.0 International License, which permits any non-commercial use, sharing, adaptation, distribution and reproduction in any medium or format, as long as you give appropriate credit to the original author(s) and the source, provide a link to the Creative Commons licence, and indicate if changes were made. The images or other third party material in this article are included in the article's Creative Commons licence, unless indicated otherwise in a credit line to the material. If material is not included in the article's Creative Commons licence and your intended use is not permitted by statutory regulation or exceeds the permitted use, you will need to obtain permission directly from the copyright holder. To view a copy of this licence, visit http://creativecommons.org/licenses/by-nc/4.0/.

\section{References}

1. Electronic Medicines Compendium: Summary of Product Characteristics for indapamide. https://www.medicines.org.uk/EMC/ medicine/26709/SPC/Indapamide+2.5mg+Tablets. Accessed 11 Nov 2020.

2. Lozol (indapamide) lebel. Available from: https://www.acces sdata.fda.gov/drugsatfda_docs/label/2009/018538s0281bl.pdf Accessed 11 Dec 2021.

3. Huerta-Alardín AL, Varon J, Marik PE. Bench-to-bedside review: rhabdomyolysis-an overview for clinicians. Crit Care. 2005;9:158-69.
4. Efstratiadis G, Voulgaridou A, Nikiforou D, Kyventidis A, Kourkouni E, Vergoulas G. Rhabdomyolysis updated. Hippokratia. 2007;11:129-37.

5. Torres PA, Helmstetter JA, Kaye AM, Kaye AD. Rhabdomyolysis: pathogenesis. Diagn Treat. 2015;15:12.

6. Jain VV, Gupta OP, Jajoo SU, Khiangate B. Hypokalemia induced rhabdomyolysis. Indian. J Nephrol. 2011;21(1):66.

7. World Health Organization Uppsala Monitoring Centre. https:// www.who-umc.org/vigibase/vigibase. Accessed 25 Dec 2021.

8. Caster O, Juhlin K, Watson S, Norén GN. Improved statistical signal detection in pharmacovigilance by combining multiple strength-of-evidence aspects in vigiRank. Drug Saf. 2014;37(8):617-28.

9. Norén GN, Hopstadius J, Bate A. Shrinkage observed-to-expected ratios for robust and transparent large-scale pattern discovery. Stat Methods Med Res. 2013;22:57-69.

10. Shakir SAW, Layton D. Causal association in pharmacovigilance and pharmacoepidemiology. Drug-Safety. 2002;25:467-71.

11. Perrio M, Voss S, Shakir SA. Application of the Bradford Hill criteria to assess the causality of cisapride-induced arrhythmia: a model for assessing causal association in pharmacovigilance. Drug Saf. 2007;30(4):333-46.

12. Ralph EI. Causality assessment in pharmacovigilance: still a challenge. Drug Saf. 2017;40:365-72.

13. Fedak KM, Bernal A, Capshaw ZA, Gross S. Applying the Bradford Hill criteria in the 21st century: how data integration has changed causal inference in molecular epidemiology. Emerg Themes Epidemiol. 2015;12:14.

14. Fabbri A, Grifoni E, Marchiani C, et al. Indapamide-induced acute hypokaliemic rhabdomyolysis in a patient with primary hyperaldosteronism. Ital J Med. 2013;7(Suppl. 2):46-7.

15. Horwitz H, Woeien VA, Petersen LW, Jimenez-Solem E. Hypokalemia and rhabdomyolysis. J Pharmacol Pharmacother. 2015;6:98.

16. van den Bosch A, van der Klooster JM, Zuidgeest DM, Ouwendijk R, Dees A. Severe hypokalaemic paralysis and rhabdomyolysis due to ingestion of liquorice. Neth J Med [Internet]. 2005;63(4):146-8.

17. Agrawal S, Agrawal V, Taneja A. Hypokalemia causing rhabdomyolysis resulting in life-threatening hyperkalemia. Pediatr Nephrol. 2006;21(2):289-91.

18. Meltem AC, Figen C, Nalan MA, Mahir K, Sebnem B, Mehlika I, et al. A hypokalemic muscular weakness after licorice ingestion: a case report. Cases J. 2009;2:8053.

19. Elinav E, Chajek-Shaul T. Licorice consumption causing severe hypokalemic paralysis. Mayo Clin Proc. 2003;78:767-8.

20. US FDA homepage. https://www.fda.gov/consumers/consumerupdates/black-licorice-trick-or-treat. Accessed 20 Nov 2020.

21. Trimarchi H, Gonzalez J, Olivero J. Hyponatremia-associated rhabdomyolysis. Nephron. 1999;82:274-7.

22. Tannen RL. Diuretic-induced hypokalemia. Kidney Int. 1985;28:988-1000.

23. Hwang KS, Kim G-H. Thiazide-induced hyponatremia. Electrolyte. Blood Press. 2010;8:51-7.

24. Antoniadis DJ, Vavouranakis EM, Tsioufis KP, Toutouzas PK. Rhabdomyolysis due to diuretic treatment, p3.

25. Shin SH, Sun DS, Kim G, Kim YS, Yoon SA, Chang YS, et al. Two cases of hypokalemic rhabdomyolysis due to thiazide treatment. Korean J Med. 2016;72:100-4.

26. Aguiar DT, Monteiro C, Coutinho P. Recurrent rhabdomyolysis secondary to hyponatremia in a patient with primary psychogenic polydipsia. Rev Bras Ter Intensiva. 2015;27:77-81.

27. Knochel JP, Schlein EM. On the mechanism of rhabdomyolysis in potassium depletion. J Clin Invest. 1972;51:1750.

28. Cooray MSA, Bulugahapitiya US, Peiris DN. Rhabdomyolysis: a rare presentation of aldosterone-producing adenoma. Indian $\mathrm{J}$ Endocrinol Metab. 2013;17:S237-9. 
29. Knochel JP. Neuromuscular manifestations of electrolyte disorders. Am J Med. 1982;72:521-35.

30. Allison RC, Bedsole DL. The other medical causes of rhabdomyolysis. Am J Med Sci. 2003;326:79-88.

31. Putterman C, Levy L, Rubinger D. Transient exercise-induced water intoxication and rhabdomyolysis. Am J Kidney Dis. 1993;21:206-9.
32. Freed MI, Rastegar A, Bia MJ. Effects of calcium channel blockers on potassium homeostasis. Yale J Biol Med. 1991;64(2):177-86.

33. Mann SJ. The silent epidemic of thiazide-induced hyponatremia. J Clin Hypertens (Greenwich). 2008;10:477-84.

34. Hazell L, Shakir SA. Under-reporting of adverse drug reactions: a systematic review. Drug Saf. 2006;29(5):385-96. 